\title{
Judicialização da educação para a efetivação do direito à educação básica
}

\section{Lawsuits in education for the realization of basic education right}

\section{Adriana A. Dragone Silveira'}

\begin{abstract}
Resumo:
Na legislação brasileira o direito à educação é declarado no conjunto dos direitos sociais, configurando-se um direito de todos e dever do Estado. Todavia, há um longo caminho a ser percorrido para que todos, sem distinção, o exerçam plenamente. Recorrer ao Poder Judiciário pode ser uma das possibilidades de efetivá-lo, conforme determinada a própria Constituição. Neste sentido, este trabalho busca apresentar a discussão acerca da judicialização da educação, como uma estratégia de implementação do direito à educação básica, analisando a literatura sobre o tema e as decisões proferidas pelo Tribunal de Justiça de São Paulo.
\end{abstract}

Palavras-chave: Direito à educação básica; Poder Judiciário; Políticas Públicas.

\begin{abstract}
:
At Brazilian law, the right to education is stated in the set of social rights, being treated as a universal right and, because of this, as a duty of the state. However, there is a hard work to transform it in reality for everyone, without distinction. Appeal to the judiciary can be a condition to its effectiveness, as determined by Brazilian Constitution. Thus, this study aims to present the discussion about the legal suits in education field as a strategy for implementing the right to basic education, analyzing the literature on the subject and the decisions of the Court of Justice of São Paulo.
\end{abstract}

Keywords: Right to basic education; Judiciary; Public Policies. 


\section{Introdução}

Os direitos educacionais estão amplamente garantidos na legislação brasileira (CURY, 1998; RANIERI, 2009); a educação é o direito social mais reforçado em termos de proteção judicial (DUARTE, 2003), no entanto há um caminho longo a se percorrer para a plena satisfação desses direitos. Assim, se os direitos são reconhecidos por um ordenamento jurídico, torna-se imprescindível que haja possibilidade de fazer com que o Poder Público cumpra com seus deveres em caso de omissão ou ação irregular.

Os procedimentos relativos ao reconhecimento formal dos direitos, à sua ampliação e especificação, fazem com que se torne cada vez mais difícil sua satisfação, dado que a proteção aos direitos sociais requer uma atuação positiva do Estado, com obrigações para a sua promoção, ao contrário dos direitos individuais tradicionais, que precisam da abstenção de determinados comportamentos² .

Ao compreender que a materialização dos direitos sociais se dá por meio da ampliação da ação do Estado, através da implementação de políticas públicas, o grande desafio, segundo Duarte (2004), "tem sido o de estabelecer mecanismos para garantir a exigibilidade e o controle judicial do seu cumprimento, em caso de ausência ou insuficiência das políticas adotadas" (p. 114). Recorrer ao Poder Judiciário é uma das possibilidades de fazer valer este direito, conforme o que determina a própria CF/88: "A lei não excluirá da apreciação do Poder Judiciário lesão ou ameaça a direito" (BRASIL, 1988, art. 5, inciso XXXV).

A inexistência das políticas públicas poderá ser objeto de controle do Poder Judiciário, pois o que qualifica a existência de um direito social como direito pleno não é simplesmente a conduta cumprida pelo Estado, mas a existência de algum poder jurídico para que o titular do direito possa, em caso de descumprimento da obrigação devida, exigir a sua autuação. Desta forma, se de verdade temos direitos, devemos ter uma ação (ABRAMOVICH, COURTIS, 2002).

\footnotetext{
2 Abramovich e Courtis (2002) destacam que todos os direitos demandam prestações positivas, sendo a diferença entre os direitos apenas de grau e que nos direitos econômicos, sociais e culturais a faceta mais visível refere-se às obrigações de fazer, por isso, às vezes são denominados por direitos de prestação.
}

No tocante ao direito social à educação, a Constituição Federal de 1988 (CF/88, art. 205) estabelece que a educação é "direito de todos e dever do Estado e da família". Os deveres do Estado para a garantia do direito à educação estão declarados no artigo 208 da CF/88, no Estatuto da Criança e do Adolescente de 1990 (ECA) e na Lei de Diretrizes e Bases da Educação Nacional de 1996 (LDB). O legislador constituinte dispensou tratamento diferenciado ao ensino obrigatório, considerando-o também como direito público subjetivo, sendo que o não-oferecimento do ensino obrigatório pelo Poder Público, ou sua oferta irregular, importa responsabilidade da autoridade competente (BRASIL, 1988, art. 208, $\S 1^{\circ}$ e $2^{\circ}$ ). A LDB/96 reforça a possibilidade da exigibilidade do ensino obrigatório, "podendo qualquer cidadão, grupo de cidadãos, associação comunitária, organização sindical, entidade de classe ou outra legalmente constituída, e, ainda, o Ministério Público, acionar o Poder Público para exigi-lo". (BRASIL, 1996, art. 5).

O ECA enumera, de forma expressa (art. 208), os direitos assegurados à criança e ao adolescente que, não oferecidos ou ofertados de maneira irregular, ensejam proteção judicial, com ações de responsabilidade. Infere-se, então, que a exigibilidade do direito à educação não se restringe ao conceito abarcado pelo direito público subjetivo, ou seja, o período declarado como obrigatório. O estatuto reconheceu que outros direitos assegurados à criança e ao adolescente, para além do atendimento ao ensino obrigatório, podem ser objeto de acionamento judicial, principalmente, considerando os deveres jurídicos do Estado.

Cabe, ainda, salientar que a formulação das políticas públicas é reservada, em regra, ao Poder Executivo, sendo imprópria a atuação judicial na conformação das políticas públicas. Todavia, a possibilidade de submeter uma política pública a controle jurisdicional é, segundo Bucci (2006), inquestionável, pois, o "Judiciário tutela as políticas públicas na medida em que elas expressam direitos" (BUCCI, 2006, p. 31).

No que diz respeito aos objetos que podem ser alvo de controle jurisdicional, quando se trata de políticas públicas em matéria de direitos fundamentais, Barcellos (2008) aponta: 
fixação de metas e prioridades; resultado final esperado; quantidade de recursos a ser investida; atendimento ou não das metas fixadas pelo próprio Poder Público; eficiência mínima na aplicação dos recursos públicos. Portanto, as metas do Plano Nacional de Educação, assim como as do orçamento público, deveriam ser alvo de controle jurisdicional.

No Brasil, os estudos sobre a exigibilidade do direito à educação pelo Sistema de Justiça estão se tornando objeto de interesse por parte de pesquisadores da área do Direito e da Educação (SILVEIRA, 2008). Algumas pesquisas e estudos, nos últimos anos, analisam, especificamente, o comportamento do Judiciário frente às demandas educacionais, por meio da análise de suas decisões (MACHADO, 2003; MACHADO JÚNIOR, 2003; GRACIANO, MARINHO, FERNANDES, 2006; LOPES, 2006; PIOVESAN, 2007; RANIERI, 2009; PANNUNZIO, 2009; CURY, FERREIRA, 2010).

Este trabalho tem por objetivo apresentar a discussão acerca da expansão do Poder Judiciário enquanto uma instância de efetivação dos direitos sociais, e nesse conjunto os educacionais, recorrendo à análise da literatura e ao levantamento de decisões proferidas pelo Tribunal de Justiça de São Paulo (TJ-SP), no período de 1991 a $2008^{3}$.

\section{Expansão do poder judiciário na implementação dos direitos sociais}

Ao longo do século XX, o Judiciário passou por um processo de expansão, tanto na função de controle de constitucionalidade das leis e dos atos normativos, como na prestação da justiça comum. O princípio da revisão judicial das leis foi gradativamente adotado por vários países. Na segunda metade deste século, houve uma expansão marcante do Judiciário, em diferentes países, tornando-se uma instância de implementação de direitos sociais e coletivos (ARANTES, 2007).

Segundo Sousa Santos et al. (1996), o desenvolvimento do Estado-providência, no período posterior à Segunda Guerra Mundial, gerou mudanças no mundo do Direito e da Justiça, com a consagração constitucional dos direitos sociais e econômicos. Com essas transformações, o Judiciário passa a ser acionado para efetivar a nova legislação social.

Com a crise do Estado-providência, a partir dos finais da década de 70 e princípios da década de 80 , as reformas orientadas pela lógica neoliberal, conduzindo à desresponsabilização do Estado de seu papel provedor e ao agravamento das desigualdades sociais, há aumento da exigibilidade do direito em um contexto de especificação dos mesmos pelos documentos internacionais e legislações nacionais.

Sousa Santos (2007), apesar de considerar as diferenças entre experiências e trajetórias dos tribunais nos países centrais, semiperiféricos e periféricos, afirma que o protagonismo emerge pela mudança política, em dois sentidos. Por um lado:

[...] o novo modelo de desenvolvimento assenta nas regras de mercado e nos contratos privados e, para que estes sejam cumpridos e os negócios tenham estabilidade, é necessário um judiciário eficaz, rápido e independente; por outro lado, a precarização dos direitos económicos e sociais passa a ser um motivo de procura do judiciário. Muita da litigação que hoje chega aos tribunais deve-se ao desmantelamento do Estado social (direito laboral, previdência social, educação, saúde, etc.). (SOUSA SANTOS, 2007, p. 17).

Outros fenômenos também influenciam a atividade judicial:

[....] a crise dos meios tradicionais de representação política e a revalorização da sociedade civil, até mesmo como espaço de produção de bens coletivos não mais realizados pelo Estado; a globalização e seus efeitos sobre a produção e implementação do Direito em suas diversas áreas; 0 agravamento de problemas que colocam em risco as instituições e a esfera pública de um modo geral, tais como a corrupção e o crime organizado. Além disso, 0 Judiciário se vê desafiado também por novos movimentos sociais, muitas vezes articulados em defesa de direitos de minorias ou de causas novas como as ambientais e dos consumidores (ARANTES, 2007, p. 100).

O recurso ao Poder Judiciário está relacionado às "culturas jurídicas e políticas, mas tem a ver, também, com um nível de efetividade da aplicação dos direitos e com a existência de estruturas administrativas que sustentam essa aplicação" (SOUSA SANTOS, 2007, p. 17). 
No que se refere, especificamente, ao crescimento da exigibilidade do direito à educação, este pode estar relacionado com a baixa efetividade dos direitos declarados e com a existência de remédios jurídicos e instituições do Sistema de Justiça que facilitam esse acionamento.

No Brasil, segundo Arantes (2007), a expansão do Judiciário ainda pode ser relacionada ao desenvolvimento e crise do Estado-providência, e, também, à ampliação do acesso à Justiça dos atores coletivos da sociedade.

Todavia, é preciso considerar que embora não tenha se construído no Brasil um Estado social semelhante ao dos países europeus, se aceita que a CF/88 seja uma tentativa de construção de um Estado de Bem-Estar Social, no sentido que reconhece os direitos sociais. No entanto, foi aprovada em um momento histórico mundial de crise deste modelo de Estado. Em outro contexto, as Emendas Constitucionais dos anos 90 retratam um processo de reforma do Estado brasileiro.

De acordo com Sousa Santos (2007), a Constituição brasileira de 1988 foi responsável pela ampliação de direitos civis, políticos, econômicos, sociais, culturais, e os de terceira geração: direitos do consumidor, meio ambiente, qualidade de vida, além de ampliar as "estratégias e instituições das quais se pode lançar mão para invocar os tribunais" (SOUSA SANTOS, 2007, p. 18). Devido a esse fato, a redemocratização e o novo marco constitucional tendem "a aumentar as expectativas dos cidadãos de verem cumpridos os direitos e as garantias consignadas na Constituição, de tal forma que, a execução deficiente ou inexistente de muitas políticas sociais pode transformar-se num motivo de recurso aos tribunais" (SOUSA SANTOS, 2007, p. 18).

Para Arantes (2007), a criação da ação civil pública, em 1985, é um marco fundamental na transformação do ordenamento jurídico brasileiro, com o reconhecimento da existência de direitos difusos e coletivos e com um processo judicial para a representação desses direitos. 0 processo de expansão da Justiça para a proteção dos direitos transindividuais se consolida na $\mathrm{CF} / 88$, que define o reconhecimento de vários outros direitos específicos, e, também, com a confirmação da função do Ministério Público (MP) na defesa desses direitos.

Para Sousa Santos (2007), as "pessoas que têm consciência de seus direitos, ao verem colocadas em causa as políticas sociais ou de desenvolvimento do Estado, recorrem aos tribunais para as protegerem ou exigirem a sua efectiva execução" (p. 19). Como nos casos das pessoas que recorrem ao Judiciário brasileiro para ter acesso a medicamentos.

Contudo, como afirma o autor supracitado, os litígios são "relações sociais que emergem e se transformam segundo dinâmicas sociologicamente identificáveis" (SOUSA SANTOS, 2007, p. 19), sendo a transformação de um conflito em demanda judicial uma "alternativa entre outras", podendo variar de país para país e entre grupo social e área de interação. Ainda, os fatores que produzem o conflito podem não ser percebidos pelo lesado, ou este não saber que é possível reagir contra o dano ou o causador. "Por essa razão, níveis baixos de litigiosidade não significam necessariamente baixa incidência de comportamentos injustamente lesivos" (SOUSA SANTOS et al., 1996, p.45).

Alguns grupos sociais "têm uma capacidade muito maior que outros para identificar os danos, avaliar a sua injustiça e reagir contra ela" (SOUSA SANTOS et al., 1996, p. 45). Já os grupos mais vulneráveis socialmente tendem a ter menor capacidade para transformar a experiência da lesão em litígio (SOUSA SANTOS et al., 1996, p. 45).

Para esses autores, depois de reconhecida a existência do dano e seu causador, o litígio só emerge se o lesado acreditar que ele pode ser reparado, reclamando com o responsável e, ainda, que "saiba fazê-lo de maneira inteligível e credível". Portanto, está implícito que os grupos sociais que têm menores capacidades de perceber o dano também apresentam dificuldade de reagir judicialmente. Assim, "elevada consciência de direitos tende a ampliar o âmbito da lesão e, correspondentemente, os objetivos da sua reparação" (idem, p. 46).

O recurso ao Judiciário para a resolução de um litígio decorre de várias alternativas e quando esta escolha ocorre, ela é de tal modo 
um processo já em recurso, pois tentativas de mecanismos informais mais acessíveis foram utilizados na resolução inicial do conflito.

No entanto, a procura pelo judiciário é apenas a "ponta do iceberg", pois há uma grande "procura suprimida". "É a procura daqueles cidadãos que têm consciência dos seus direitos, mas que se sentem totalmente impotentes para os reivindicar quando são violados" (SOUSA SANTOS, 2007, p. 31). Nesta "procura suprimida", além dos que têm consciência de seus direitos é necessário considerar os que estão alijados do conhecimento de seus direitos.

Sadek (2004) destaca que as dificuldades de acesso ao Judiciário são um fator inibidor da realização da cidadania plena. E no Brasil o sistema judicial estimula um "paradoxo demandas de menos e demandas de mais":

[...] de um lado, expressivos setores da população acham-se marginalizados dos serviços judiciais, utilizando-se, cada vez mais, da justiça paralela, governada pela lei do mais forte, certamente menos justa e com altíssima potencialidade de desfazer todo o tecido social. De outro, há os que usufruem em excesso da justiça oficial, gozando das vantagens de uma máquina lenta, atravancada e burocratizada (SADEK, 2004, p. 86).

O Poder Judiciário, nesse processo de expansão, assume funções relevantes na resolução de litígio; contudo, como destaca Sousa Santos (1996, 2007), nem todos os cidadãos procuram essa alternativa, principalmente os que não têm consciência de seus direitos e da possibilidade de acessar as estruturas do Poder Judiciário para exigir a sua concretização.

\section{Judicialização: Principais Aspectos}

O fenômeno da expansão da judicialização da política é uma expressão utilizada pela ciência social e pelo direito, a partir do trabalho de Tate e Vallinder (1995), que abordam esse processo em diversos países do mundo. Para os autores, algumas condições facilitam a judicialização, como: a democracia; a separação de poderes; o reconhecimento formal de direitos; a consciência dos meios judiciais pelos grupos de interesses e pelos partidos de oposição na realização de seus objetivos; inefetividade das instituições majoritárias; a incapacidade das instituições em dar provimento às demandas sociais, delegando às cortes a tomada de decisão em determinadas áreas da política.

Para Rios-Figueroa e Taylor (2006), a judicialização da política está relacionada ao deslocamento crescente dos conflitos políticos das arenas tradicionais (Legislativo e Executivo) para o Judiciário, configurando-se a estrutura institucional um dos principais determinantes para o padrão/modelo de judicialização de política, sendo que as características institucionais do sistema jurídico, como a independência e a revisão judicial, influenciam no padrão de contestação de políticas.

Segundo Cury e Ferreira (2010), o processo de judicialização da educação ocorre "quando aspectos relacionados ao direito à educação passam a ser objeto de análise e julgamento pelo poder judiciário". Esse fenômeno se verifica quando da ofensa ao direito à educação decorrentes de: "(a) mudanças no panorama legislativo; (b) reordenamento das instituições judicial e escolar; (c) posicionamento ativo da comunidade na busca pela consolidação dos direitos sociais" (p.81).

Para Barroso (2009, p. 331), a judicialização significa que "algumas questões de larga repercussão política ou social estão sendo decididas por órgãos do Poder Judiciário, e não pelas instâncias tracionais".

Segundo Vianna et al. (1999), o processo de judicialização política no Brasil tem sido resultado de uma progressiva apropriação das inovações da Constituição de 88 por parte da sociedade e de agentes institucionais. Na nova arena política brasileira, dois atores exercem papel relevantenesse processo: os governadores e os procuradores. No entanto, o processo de judicialização no Brasil tem um caráter dúplice. De um lado, uma característica comum como a descrita pela bibliografia sobre o assunto, as minorias parlamentares demandam a intervenção do Judiciário contra a vontade da maioria; por outro lado, se afasta dessa característica com a ação dos Executivos estaduais e da Procuradoria da República contra a representação parlamentar, em sua maioria de âmbito estadual, indicando que a sociedade e a 
federação se encontram desajustadas da vontade do soberano e têm reclamado a presença de um terceiro na resolução dos problemas.

A ineficiência das instituições majoritárias relaciona-se à incapacidade dessas instituições em dar provimento às demandas sociais. "Alguns tribunais, diante da inércia dos políticos e da impossibilidade de negarem uma decisão, são obrigados a pôr um fim em conflitos que deveriam ser resolvidos no âmbito político". No entanto, destaca que "toda demanda social que não envolva interesse suficiente ou agregue alto custo certamente encontrará dificuldade para ser efetivada. (CARVALHO, 2004, p. 120). Essa posição de cautela é verificada no Brasil, segundo o autor, em momentos de crise; como exemplo cita a crise de governabilidade do final da década de 1980 e início da de 1990, com uma opção clara do Supremo Tribunal Federal - STF pela não-interferência.

O aumento do número de processos pode não implicar em intervenção efetiva do Judiciário. Como indaga Carvalho, "até que ponto os juízes modificam as leis ou atos dos demais poderes? Ou "até que ponto essas decisões interferem na aplicação de políticas públicas?" (2004, p. 121).

A judicialização da política requer que os [...] operadores da lei prefiram participar da policymaking a deixá-la ao critério de políticos e administradores e, em sua dinâmica, ela própria implicaria papel político mais positivo da decisão judicial do que aquele envolvido em uma não decisão. Daí que a idéia de judicialização envolve tanto a dimensão procedimental quanto substantiva do exercício das funções judiciais (MACIEL, KOERNER, 2002, p. 114).

O fenômeno da judicialização da política não deve ser considerado apenas com os índices de acionamento do Judiciário (CARVALHO, 2004; PACHECO, 2006), mas é preciso analisar as respostas dadas pelo Judiciário aos questionamentos, ou seja, os resultados políticos produzidos a partir do acionamento da via judicial.

De acordo com Barroso (2009), é preciso esclarecer a diferença entre judicialização e ativismo judicial, que são "primos", mas não tem a mesma origem.

A judicialização, no contexto brasileiro, "é uma circunstância que decorre do modelo constitucional que se adotou, e não um exercício deliberado de vontade política", pois "se uma norma constitucional permite que dela se deduza uma pretensão, subjetiva ou objetiva, ao juiz cabe dela conhecer, decidindo a matéria" (BARROSO, 2009, p. 335).

Já o ativismo judicial é:

[...] uma atitude, uma escolha de um modo específico e proativo de interpretar a Constituição, expandindo 0 seu sentido e alcance. Normalmente ele se instala em situações de retração do Poder Legislativo, de um certo deslocamento entre a classe política e a sociedade civil, impedindo que as demandas sociais sejam atendidas de maneira efetiva" (BARROSO, 2009, p. 335).

Uma atitude oposta ao ativismo é a "autocontenção judicial", quando o Judiciário procura reduzir sua interferência nas ações dos outros Poderes. Nesta linha, juízes e tribunais:

(i) evitam aplicar diretamente a Constituição a situações que não estejam no seu âmbito de incidência expressa, aguardando o pronunciamento do legislador ordinário; (ii) utilizam critérios rígidos e conservadores para a declaração de inconstitucionalidade de leis e atos normativos; (iii) abstêm-se de interferir na definição das políticas públicas (BARROSO, 2009, p. 336).

A intervenção dos Tribunais nos processos decisórios de problemas eminentemente políticos não é consenso, sendo os integrantes dessas instituições constantemente questionados, principalmente no caráter democrático desta intervenção.

Nos últimos anos, o Poder Judiciário brasileiro, especialmente o STF, tem julgado ações de grande repercussão política e social, evidenciando o deslocamento de questões políticas do âmbito do Executivo e Legislativo para o Judiciário, colocando em destaque o papel político dos integrantes desta Corte.

Para Sousa Santos et al. (1996), nos países semiperiféricos e periféricos os Tribunais estão assumindo, de maneira lenta e fragmentada, uma co-responsabilidade política na atuação do Estado providência. "A distância entre a Constituição e o direito ordinário é, nesses países, enorme, e os tribunais têm sido, em geral, tíbios em tentar encurtála". Dentre os fatores para essa atuação destaca: o conservadorismo dos magistrados, formados em faculdades de Direito dominadas "por concepções retrógradas da relação entre direito e sociedade"; 
desempenho rotinizado,"politicamente hostil à justiça distributiva e tecnicamente despreparado para ela"; "cultura jurídica 'cínica' que não leva a sério a garantia dos direitos", (Referência bibliográfica, pg.) considerando os direitos constitucionalmente consagrados como declarações programáticas; organização judiciária deficiente em recursos técnicos e humanos; "um Poder Judicial tutelado por um Poder Executivo, hostil à garantia dos direitos ou sem meios orçamentais para levar a cabo; a ausência de opinião pública forte e de movimentos sociais organizados para a defesa dos direitos; um direito processual hostil e antiquado" (p. 38-9).

O Judiciário ao assumir uma atitude mais ativa torna-se "mais controverso, mais visível e vulnerável politicamente" (SOUSA SANTOS, 2007, p. 23). Em alguns países, subsiste uma transferência de legitimidade do Poder Executivo e Legislativo para o Judiciário. Esse "movimento leva a que se criem expectativas positivas elevadas a respeito do sistema judiciário, esperando-se que resolva os problemas que o sistema político não consegue resolver" (SOUSA SANTOS, 2007, p.21). E o Judiciário, em grande medida, não consegue corresponder à expectativa.

Nos últimos tempos, algumas críticas ao Poder Judiciário permeiam o debate na sociedade brasileira, como: moroso e inepto como prestador de serviço, portanto incapaz de responder à crescente demanda e que sua instituição é refratária às modificações.

De acordo com Sadek (2004), o Poder Judiciário é um serviço público com extraordinária procura, no entanto são julgados, em média, $72 \%$ dos processos ingressados. "Calculase que, caso cessassem de ingressar novos casos, seriam necessários de cinco a oito anos, dependendo do ramo do Judiciário e da unidade da federação para que fossem colocados em dia todos os processos existentes" (p. 88).

De acordo com Barroso, "o Judiciário é o guardião da Constituição e deve fazê-la valer, em nome dos direitos fundamentais e dos valores e procedimentos democráticos, inclusive em face dos outros Poderes. Eventual atuação contramajoritária, nessas hipóteses, se dará a favor, e não contra a democracia". (BARROSO,
2009, p. 346). Todavia, o próprio autor destaca que o ativismo judicial não é a solução para o problema brasileiro:

Mas ele é um antibiótico poderoso, cujo uso deve ser eventual e controlado. Em dose excessiva, há risco de se morrer da cura. A expansão do Judiciário não deve desviar a atenção da real disfunção que aflige a democracia brasileira: a crise de representatividade, legitimidade e funcionalidade do Poder Legislativo. Precisamos de reforma política. E esta não pode ser feita por juízes (BARR0S0, 2009, p. 346).

Sobre o papel do Judiciário, e sua relação de independência dos demais poderes, destacase como relevante a discussão feita por Sousa Santos (2007):

É evidente que o sistema judicial não pode resolver todos os problemas causados pelas múltiplas injustiças. Mas, tem que assumir a sua quota-parte de responsabilidade na resolução. 0 sistema judicial está, hoje, colocado perante o seguinte dilema. Se não assumir a quota-parte da sua responsabilidade, continuará a ser independente de um ponto de vista corporativo, mas será cada vez mais irrelevante tanto social como politicamente (SOUSA SANTOS, 2007, p. 34).

Concorda-se com o autor, pois em uma sociedade democrática o Judiciário tem o dever de assumir o seu papel de controlar a implementação dos direitos consagrados na legislação, exigindo dos demais poderes a sua realização.

\section{Decisões educacionais do Tribunal de Justiça de São Paulo}

Pesquisa realizada sobre as decisões do Tribunal de Justiça de São Paulo (TJ-SP) envolvendo o direito de crianças e adolescentes à educação, após a implantação do ECA ${ }^{4}$, entre o período de 1991 a 2008, com a análise de 483 documentos, evidenciou o uso do Poder Judiciário para a efetivação e/ou questionamento das políticas públicas envolvendo à educação, conforme quadro a seguir. Todavia, o levantamento das decisões

\footnotetext{
4 A escolha pelo período de análise das decisões após a implantação do ECA considerou que esta lei foi um importante ordenador jurídico para a defesa dos direitos da infância e da juventude, especialmente com inovações no campo de atuação do MP para a garantia do direito da criança e do adolescente, e incluindo nesse conjunto 0 direito à educação. Outro fator que fundamentou a escolha por esse período é a afirmação de Oliveira (2007), também confirmada por Silveira (2006), de que o Estatuto é utilizado como fundamento legal para as ações visando à garantia do direito à educação.
} 
judiciais denota com mais expressão o uso do Poder Judiciário em algumas áreas. O recurso judicial para requisição de uma vaga na educação básica e para o oferecimento de serviços que impedem a permanência do aluno na escola foram os conflitos mais presentes no conjunto estudado.

\section{Quadro 1 - Organização das decisões por categorias e temas}

\begin{tabular}{|c|c|c|}
\hline CATEGORIAS & TEMAS & $\begin{array}{c}n^{0} \text { de } \\
\text { decisões }\end{array}$ \\
\hline \multirow{7}{*}{$\begin{array}{c}\text { ACESSO À } \\
\text { EDUCAÇÃO BÁSICA }\end{array}$} & Educação Infantil & 175 \\
\hline & Ensino Fundamental & 73 \\
\hline & Ensino Médio & 1 \\
\hline & EJA & 6 \\
\hline & Educação Profissional & 10 \\
\hline & Educação Especial & 17 \\
\hline & $\begin{array}{l}\text { Não define a etapa/ } \\
\text { modalidade }\end{array}$ & 2 \\
\hline \multirow{4}{*}{ PERMANÊNCIA } & $\begin{array}{c}\text { Violação às normas } \\
\text { escolares }\end{array}$ & 15 \\
\hline & $\begin{array}{l}\text { Cancelamento de } \\
\text { matrícula em curso de } \\
\text { língua estrangeira }\end{array}$ & 11 \\
\hline & Evasão escolar & 4 \\
\hline & Outras & 6 \\
\hline \multirow{3}{*}{$\begin{array}{c}\text { RESPONSABILIDADE } \\
\text { ESTATAL }\end{array}$} & Transporte & 14 \\
\hline & $\begin{array}{l}\text { Ações de reparação de } \\
\text { danos }\end{array}$ & 18 \\
\hline & $\begin{array}{c}\text { Condições de } \\
\text { funcionamento das } \\
\text { escolas }\end{array}$ & 3 \\
\hline \multirow{2}{*}{$\begin{array}{l}\text { PODER DE } \\
\text { REGULAÇÃO0 } \\
\text { ESTATAL }\end{array}$} & Mensalidade Escolar & 46 \\
\hline & $\begin{array}{l}\text { Autorização / } \\
\text { credenciamento }\end{array}$ & 21 \\
\hline \multirow{5}{*}{$\begin{array}{l}\text { DECISÕES } \\
\text { ADMINISTRATIVAS } \\
\text { E POLITICAS }\end{array}$} & $\begin{array}{c}\text { Competência para } \\
\text { legislar }\end{array}$ & 23 \\
\hline & $\begin{array}{l}\text { Reorganização das } \\
\text { escolas estaduais }\end{array}$ & 2 \\
\hline & Municipalização & 3 \\
\hline & $\begin{array}{l}\text { Fechamento de creche } \\
\text { no período de férias }\end{array}$ & 2 \\
\hline & Outras & 6 \\
\hline \multirow{4}{*}{$\begin{array}{l}\text { GESTÃO DOS } \\
\text { RECURSOS } \\
\text { PÚBLICOS }\end{array}$} & $\begin{array}{l}\text { Aplicação mínima de } \\
\text { recursos }\end{array}$ & 8 \\
\hline & Fundef & 1 \\
\hline & Contratos & 2 \\
\hline & $\begin{array}{l}\text { Repasse de recursos } \\
\text { públicos às instituições } \\
\text { privadas }\end{array}$ & 3 \\
\hline DEVERES DOS PAIS & $\begin{array}{l}\text { Responsabilidade dos } \\
\text { pais e responsáveis }\end{array}$ & 11 \\
\hline
\end{tabular}

Fonte: SILVEIRA, 2010.
Nesta pesquisa foi possível perceber um crescimento das demandas a partir da aprovação da LDB/96. Até 1995, as demandas são mais esparsas, destacando-se as decisões acerca do controle de mensalidades escolares no setor privado. Mesmo considerando que as decisões analisadas não correspondem ao total de julgados, ainda assim denotase um acentuado número nos anos de 1998, 2006, 2007 e 2008, todavia alguns litígios são discutidos em períodos específicos, a partir de atos do Poder Público, sejam elespor omissão ou por ação, que impedem que o direito à educação seja garantido.

Os últimos anos apresentaram um número maior de decisões, todavia não se trata de expansão das mesmas demandas. Com exceção das que requisitaram vagas em instituições de Educação Infantil (El), a maioria das ações é levada a litígio em períodos específicos, ocasionadas por alterações nas políticas de oferta do atendimento educacional e na legislação.

A busca pelo Judiciário, como já enfatizado, é sempre um processo em recurso (SOUSA SANTOS, 1996), pois tentativas informais, visando à resolução do conflito, são feitas com as próprias instituições encarregadas de garantir o direito, como a procura pelos pais, na escola; as intervenções do Conselho Tutelar e do MP, valendo-se de instrumentos extrajudiciais. Em outros casos, o ingresso com a ação judicial corresponde a uma tentativa de evitar reformas nas políticas educacionais, como a municipalização do EF e reorganização das escolas estaduais, sendo a tutela jurisdicional, para as entidades de classe como a Apeoesp, uma das tentativas de reversão da política e de defesa dos interesses da categoria. Porém, como destacado por Carvalho (2004), as demandas sociais que não agregam interesse suficiente, ou que envolvem altos custos para que sejam efetivadas, têm mais dificuldade de ser acatadas pelo Judiciário, que opta por posição de não-interferência.

O total de decisões coletadas no âmbito do TJ-SP evidencia o acionamento do Judiciário, mas, para que o fenômeno da judicialização 
ocorra é preciso analisar as respostas do Judiciário, com as mudanças produzidas a partir da participação de seus membros no processo decisório de implementação dos direitos sociais, no entanto, considerando o objetivo deste trabalho não será possível seu desenvolvimento.

No que diz respeito ao acionamento do Judiciário paulista para os conflitos educacionais, cumpre reafirmar que este é realizado em períodos específicos, com inequívoca relação, sobretudo, com mudanças no contexto econômico; relacionandose, ainda, às ações sobre reajustes de mensalidades e à normatização nos processos sobre ingresso dos alunos com seis anos no Ensino Fundamental (EF), orientações para autorização e credenciamento das instituições privadas na oferta de Educação de Jovens e Adultos (EJA), critérios para as matrículas nos cursos de língua estrangeira oferecidos pela rede estadual. As demandas por vagas em instituições de El, iniciadas no final da década de 90 e constantemente apreciadas pelo TJ-SP, podem estar ligadas à restrição de recursos mediada pela EC n¹4/96, que priorizou o financiamento ao EF, e à declaração como primeira etapa da educação básica pela LDB/96. Também, é importante ressaltar nesse processo a valorização por parte da sociedade da educação anterior ao período obrigatório como uma etapa fundamental de formação das crianças.

Neste cenário de crescente exigibilidade do direito à educação merece destaque o papel exercido pelo MP, que atuou como parte em número considerável de decisões proferidas pelo TJ-SP.

\section{Considerações Finais}

A utilização do Judiciário para reivindicar e questionar políticas relacionadas à educação, principalmente nesta década, tem permitido mudança de atitude por parte dos membros do Judiciário. Um exemplo paradigmático referese à exigibilidade da El. Inicialmente, com sentenças diferenciadas em primeira instância, e até mesmo por parte dos desembargadores do TJ-SP. Desse modo, consolidou-se uma jurisprudência favorável ao longo dos anos, sobretudo, com as decisões proferidas pelo STF. Sabe-se que as decisões favoráveis conferem maior visibilidade à possibilidade de reclamar e conseguir judicialmente o direito pretendido.

Apesar do papel do Judiciário na educação ter se ampliado de forma expressiva, é patente a necessidade de discutir a utilização deste meio para a resolução de litígios envolvendo questões pedagógicas e educativas, pois esta instituição nem sempre será o mecanismo mais eficaz, devido ao despreparo dos seus membros para as dinâmicas envolvendo o cotidiano educacional.

Em decorrência do processo de acionamento do Judiciário, é preciso, também, considerar a sobrecarga de trabalho existente nos Tribunais. A morosidade no julgamento e os diversos recursos para uma decisão final podem afetar as expectativas de utilização do Judiciário como um mecanismo capaz de responder às demandas da sociedade que reivindicam a efetivação dos direitos sociais.

Sobre a utilização do Judiciário para reivindicar junto ao Poder Público a implementação de direitos, e para questionar políticas envolvendo a educação, não é possível ignorar a conscientização da população e da sociedade civil organizada sobre seus direitos e sobre a viabilidade de recorrerem aos Tribunais nestas questões, facultando que o Judiciário já não seja apenas uma instituição focada na resolução de conflitos entre particulares. Antes, os Tribunais, como referido por Sousa Santos (2007), são vistos como uma arma dos movimentos sociais para fazer com que os direitos sejam levados a sério. 


\section{Referências Bibliográficas}

ABRAMOVICH, V.; COURTIS, C. Los derechossociales como derechosexigibles. Madrid: Editorial Trotta, 2002.

ARANTES, R. B. Judiciário: entre a Justiça e a Política. In: AVELAR, L.; CINTRA, A. O. Sistema político brasileiro: uma introdução. 2. ed. Rio de Janeiro: Konrad-Adenauer-Stiftung; São Paulo: Editora Unesp, 2007.

BARCELLOS, A. P. Constitucionalização das políticas públicas em matéria de direitos fundamentais: o controle político-social e o controle jurídico no espaço democrático. In: SARLET, I. W.; TIMM, L. B. (Org.). Direitos Fundamentais: orçamento e "reserva do possível". Porto Alegre: Livraria do Advogado, 2008.

BARROSO, L. R. O controle de constitucionalidade no direito brasileiro: exposição sistemática da doutrina e análise crítica da jurisprudência. $4^{\mathrm{a}}$ ed. São Paulo: Saraiva, 2009.

BRASIL. Constituição da República Federativa do Brasil de 1988, Brasilia. Disponível em:<http://www.senado.gov.br/st/legislacao/ const/>. Acesso em: 14 ago. 2009.

Lei $\mathbf{n}^{\circ} \mathbf{8 . 0 6 9}$, de 13 de julho de 1990. Dispõe sobre o Estatuto da Criança e do Adolescente e dá outras providências. Diário Oficial da União: República Federativa do Brasil, Brasilia, DF, 16 de julho de 1990.

. Lei n. 9.394, de 20 de dezembro de 1996. Estabelece as Diretrizes e Bases da Educação Nacional. Disponível em: <http://www. presidencia.gov.br/ccivil_03/Leis/L9394.htm >. Acesso em: 20 jan. 2009.

BUCCI, M. P. D. 0 conceito de política pública em direito. In: BUCCI, M. P. D. (Org.). Políticas Públicas: reflexões sobre o conceito jurídico. São Paulo: Saraiva, 2006.

CURY, C. R. J. A educação infantil como direito. In:BRASIL, Ministério da Educação e do Desporto. Subsídios para credenciamento e funcionamento de instituições de educação infantil. Volume II. Brasília: MEC, 1998.

; FERREIRA, L. A. M. Justiciabilidade no campo da educação. Revista de Política e Administração da Educação. Porto Alegre: ANPAE, v. 26, n. 1, p. 75103, jan/ abr. 2010.

CARVALHO, E. R. de. Em busca da judicialização da política no Brasil: apontamentos para uma nova abordagem.Revista Brasileira de Ciências Sociais. Curitiba, n. 23, 2004.

DUARTE, C. S. O direito público subjetivo ao ensino fundamental na Constituição Federal Brasileira de 1988. 2003. 328 p. Tese (Doutorado) - Faculdade de Direito, Universidade de São Paulo, São Paulo, 2003.

. Direito público subjetivo e políticas educacionais. São Paulo em Perspectiva. São Paulo, n. 18 (2), p. 113-118. 2004.

GRACIANO, M. G.; MARINHO, C.; FERNANDES, F. As demandas judiciais por educação na cidade de São Paulo. In: HADDAD, S.; GRACIANO, M. (Org.) A educação entre os direitos humanos. Campinas, SP: Autores Associados; São Paulo, SP: Ação Educativa, 2006.

LOPES, J. R. de L. Direitos sociais: teoria e prática. São Paulo: Método, 2006.

MACHADO, E. A Jurisprudência educacional do Supremo Tribunal Federal, na vigência da Constituição de 1988 da República Federativa do Brasil. 2003. p. 122. Dissertação (Mestrado) - Faculdade de Educação, Universidade de São Paulo, São Paulo, 2003.

MACHADO JÚNIOR, C. P. da S. O direito à educação na realidade brasileira. São Paulo: LTr, 2003.

MACIEL, D. A.; KOERNER, A. Sentidos da judicialização da política: duas análises. Lua Nova. São Paulo, n. 57, 2002.

OLIVEIRA, R. L. P. de. 0 direito à educação. In: OLIVEIRA, R. P. de; ADRIÃO, T. (Org.). Gestão, financiamento e direito à educação: análise da LDB e da Constituição Federal. $3^{a}$ ed. São Paulo: Xamã, 2007.

PACHECO, C. C. O Supremo Tribunal Federal e a Reforma do Estado: uma análise das Ações Diretas de Inconstitucionalidade julgadas no primeiro mandato de Fernando Henrique Cardoso (1995-1998). 2006. Tese (Doutorado). Programa de pós-graduação em Ciências Sociais, Universidade Estadual de Campinas, Campinas, São Paulo, 2006.

PANNUNZIO, E. 0 Poder Judiciário e o Direito à Educação. In: RANIERI, N. B. S. (Coord.); RIGHETTI, S. Direito à educação: aspectos constitucionais. São Paulo: Editora da Universidade de São Paulo, 2009.

PIOVESAN, F. Justiciabilidade dos direitos sociais e econômicos: desafios e perspectivas. In: SILVA, R. B. D. da (Coord.). Direito Constitucional. São Paulo: Método, 2007.

RANIERI, N. B. S. Os Estados e o direito à educação na Constituição de 1988: comentários acerca da jurisprudência do Supremo Tribunal Federal. In: RANIERI, N. B. S. (Coord.); RIGHETTI, S. Direito à educação: aspectos constitucionais. São Paulo: Editora da Universidade de São Paulo, 2009.

RIOS-FIGUEROA, J.; TAYLOR, M. Institucional DeterminatsoftheJudicialisationofpolicy in Braziland México. Journal of Latin American Studies. Cambridge University Press, United Kingdom, 38, 2006, p. $739-766$. 
SADEK, M. T. Judiciário: mudanças e reformas. Revista Estudos Avançados. Vol. 18, número 51, ago./maio 2004. p 79-101.

SILVEIRA, A. A. D. Direito à educação e o Ministério Público: uma análise da atuação de duas Promotorias de Justiça da Infância e Juventude do interior paulista. 2006. 262p. Dissertação (Mestrado) - Faculdade de Educação, Universidade de São Paulo, São Paulo, 2006.

. A exigibilidade do direito à educação básica pelo Sistema de Justiça: uma análise da produção brasileira do conhecimento. Revista Brasileira de Polt́tica e Administração da Educação. Porto Alegre: Anpae, v.24, n.3, p. 537-555, set./dez. 2008.

O direito à educação de crianças e adolescentes: análise da atuação do Tribunal de Justiça de São Paulo (1991-2008). 2010. 303 p. Tese (Doutorado). Faculdade de Educação, Universidade de São Paulo, 2010.

SOUSA SANTOS, B. et al. Os tribunais nas sociedades contemporâneas: o caso português. Porto: Edições Afrontamento, 1996.

SOUSA SANTOS, B. Para uma revolução democrática da justiça. São Paulo: Cortez, 2007.

TATE, N.; VALLINDER; T. (Ed.). The Global Expansion of Judicial Power. New York: New York University Press, 1995.

VIANNA, L. W. et al. A judicialização da política e das relações sociais no Brasil. Rio de Janeiro: Editora Revan, 1999. 